\title{
SEROPREVALENCE OF PANDEMIC H1N1 INFLUENZA AMONG PREGNANT WOMEN IN KERALA, INDIA
}

\author{
Anuja Ushakumari1, Mini Sreedharan Suseela², Retheesh Kollerazhikathu Haridasan ${ }^{3}$
}

${ }^{1}$ Additional Professor, Department of Community Medicine, Government Medical College, Thiruvananthapuram.

${ }^{2}$ Associate Professor, Department of Community Medicine, Government Medical College, Kollam.

${ }^{3}$ Assistant Professor, Department of Community Medicine, Government Medical College, Thiruvananthapuram.

\section{ABSTRACT}

\section{BACKGROUND}

Pandemic influenza affected all sections of the society with maximum involvement among younger population. Pregnant females were at high risk for severe disease and complications. ${ }^{1}$ This study was conducted to estimate the seroprevalence of pandemic H1N1 influenza among pregnant women in Kerala.

\section{MATERIALS AND METHODS}

A cross sectional study was conducted in three badly affected districts of Kerala during the post-pandemic period. Sample size was calculated with prevalence of $32 \%,{ }^{2} \alpha$ error $5 \%$, relative precision $20 \%$ and design effect of 1.5 . Univariate analysis was done and proportions were calculated. Blood samples were collected from 355 pregnant women who participated in the study. ELISA, using a monoclonal antibody ( $\mathrm{mAb}$ ) against influenza A Haemagglutinin protein (HP) was done to detect antibodies against influenza.

\section{RESULTS}

Two third of the study population were housewives, high school educated and socioeconomically in the lower class. $98.3 \%$ of them were ELISA positive indicating that almost all of them were exposed to pandemic H1N1 influenza during the pandemic period.

\section{CONCLUSION}

Most of the pregnant women developed protective antibodies against pandemic H1N1 influenza, hence got public health relevance.

\section{KEYWORDS}

Seroprevalence, Pandemic H1N1 Influenza, ELISA.

HOW TO CITE THIS ARTICLE: Ushakumari A, Suseela MS, Haridasan RK. Seroprevalence of pandemic H1N1 influenza among pregnant women in Kerala, India. J. Evolution Med. Dent. Sci. 2017;6(31):2533-2536, DOI: 10.14260/Jemds/2017/548

\section{BACKGROUND}

Pandemic H1N1 influenza affected millions of people in the world and caused considerable morbidity and mortality among general public. This pandemic was caused by a novel virus of swine origin resulting in the occurrence of the first pandemic in 40 years. ${ }^{3}$ In Kerala, there were 3322 confirmed cases and 131 deaths in the pandemic period, and this is expected to continue for few seasons after the pandemic was called off in November 2010 till most of the people acquire immunity against it. ${ }^{4}$ In Kerala, most of the cases were reported from southern districts and it occurred among all sections of the society with uniform distribution among all age groups. ${ }^{5}$

Pregnant women represent the active young population of the community and they were exposed to H1N1 during the pandemic period during their pre-pregnancy period. Pregnant status increases the risk for severe disease 4-5 times and this risk is highest in the third trimester. ${ }^{1}$ This is because mother's body is rapidly changing, especially the cardiovascular, respiratory and immune systems.

Financial or Other, Competing Interest: None.

Submission 13-03-2017, Peer Review 06-04-2017,

Acceptance 12-04-2017, Published 17-04-2017.

Corresponding Author:

Anuja Ushakumari,

Additional Professor,

Department of Community Medicine,

Government Medical College,

Thiruvananthapuram.

E-mail: anuja_balachandran@yahoo.com

DOI: $10.14260 /$ jemds $/ 2017 / 548$

\section{(c) (i) $\$$}

Influenza in pregnancy is also associated with an increased risk of adverse pregnancy outcomes ${ }^{6,7}$, such as spontaneous abortion, preterm birth, and foetal distress. To know the extent of spread of pandemic H1N1 influenza in the community, this study was carried out during the postpandemic period with the objective to estimate the seroprevalence of pandemic H1N1 influenza among pregnant women in Kerala.

\section{MATERIALS AND METHODS \\ Study Design}

Hospital based cross sectional study was conducted to find out the seroprevalence of pandemic H1N1 influenza among pregnant women in Kerala.

\section{Study Setting}

Kerala was one of the badly affected states during the pandemic H1N1 influenza in India. ${ }^{8}$ This study was carried out in three out of 14 districts of Kerala namely Thiruvananthapuram, Kollam and Pathanamthitta. Study participants recruited from all general, district and taluk hospitals in these districts formed the sampling unit. A total of 38 institutions were included in the study.

\section{Study Subjects and Study Period}

Pregnant women attending antenatal clinics were recruited for the study. In Kerala, the spread of pandemic H1N1 influenza occurred during the years 2009 and 2010. This study was conducted during the post-pandemic period from May to September 2011. 


\section{Sample Size and Sampling Technique}

Seroprevalence among general population varies from $20 \%$ $40 \%$ during pandemics. ${ }^{9}$ Expecting the same prevalence among pregnant women, sample size was calculated with prevalence of $30 \%$, $\alpha$ error $5 \%$, $\beta$ error $20 \%$ and design effect of 1.5 , sample size required for the study was estimated to be 350. From each sampling unit, 10 eligible people were recruited resulting in a final sample size of 355.

\section{Ethical Consideration}

Study was carried out after obtaining clearance from institution research committee and human ethics committee. Written informed consent was also obtained from each of the participant after explaining the purpose of the study. Study was conducted in accordance with the standards of ethics committee.

\section{Data Collection}

Study was conducted after obtaining permission from the heads of the institution. From each hospital either a staff nurse or a laboratory technician was identified and one day training was given to them for data collection. Pregnant women were recruited from a total of 38 secondary level care government hospitals in three selected districts of Kerala. All pregnant women seeking antenatal care from these hospitals constituted the study population and from each hospital ten participants were recruited for the study by consecutive sampling technique.

After obtaining written informed consent from each study participant, information regarding sociodemographic factors, pregnancy related factors namely gestational age and parity were collected using pre-tested structured questionnaire. From each participant 3-5 mL of blood was collected and safely transported at $4-8^{\circ} \mathrm{C}$ to testing laboratory for serological analysis.

H1N1 virus possesses haemagglutinin, the antigenic surface protein which mediates the entry of virus in to host cell and this is the most important antigen against which neutralising antibodies are directed.10 In this study, ELISA using a monoclonal antibody $(\mathrm{mAb})$ against influenza $\mathrm{A}$ Haemagglutinin protein (HP) - A/California/07/2009 was used to detect antibodies against influenza. Where H1N1 antigen was used as positive control, H1N1 negative human serum as negative control and patient serum were diluted from 1:10 to 1:2560. Wells with serum and positive control turn blue as Anti-H1N1 primary antibody recognises and binds specifically to $\mathrm{H} 1 \mathrm{~N} 1$ antigen and Horseradish peroxidase (HRP) - labelled secondary antibody recognises and binds specifically to anti-H1N1 primary antibody and will not wash away, HRP will oxidise the enzyme substrate, which will result in a blue colour. Wells with negative control will remain colourless. If the well with the samples at a dilution of 1:40 or more turns blue, it indicates the presence of H1N1 antibody. If the well remains colourless, then the H1N1 antigen is not present and the ELISA result is read as negative.

\section{RESULTS}

A hospital based cross sectional study was carried out to find out seroprevalence of pandemic H1N1 influenza among pregnant women in three districts of Kerala during postpandemic period. Study participants were recruited from all secondary level health care institutions in public sector. Of the 355 study participants, 51\% (n=181) were from Ernakulam, $30 \%(n=106)$ from Thiruvananthapuram and 19\% $(n=68)$ from Kollam. Almost half the study population was in 21-25 year age group, Seventy two percent of the study participants completed high school education and $77 \%$ were unemployed. Socioeconomic status was assessed using Kuppuswamy's socioeconomic status scale ${ }^{11}$ based on education, occupation and income. Three fourth of the population (72.9\%) belonged to poor socioeconomic status. District wise distribution of sociodemographic factors of 355 participants are given in Table 1.

\begin{tabular}{|c|c|c|c|c|c|c|c|c|}
\hline \multirow{2}{*}{$\begin{array}{c}\text { Study Variables } \\
\text { Age in Years }\end{array}$} & \multicolumn{2}{|c|}{ Thiruvananthapuram $(n=106)$} & \multicolumn{2}{|c|}{ Kollam (n=68) } & \multicolumn{2}{|c|}{ Ernakulam $(n=181)$} & \multicolumn{2}{|c|}{ Total $(n=355)$} \\
\hline & Number & $\%$ & Number & $\%$ & Number & $\%$ & Number & $\%$ \\
\hline $18-20$ & 18 & 17.0 & 9 & 13.2 & 18 & 9.9 & 45 & 12.7 \\
\hline $21-25$ & 57 & 53.8 & 29 & 46.6 & 76 & 42.0 & 162 & 45.6 \\
\hline $26-30$ & 22 & 20.8 & 23 & 33.8 & 62 & 34.3 & 107 & 30.1 \\
\hline 31 and above & 9 & 8.5 & 7 & 10.3 & 25 & 13.8 & 41 & 11.6 \\
\hline \multicolumn{9}{|c|}{ Education } \\
\hline Below SSLC & 37 & 35 & 39 & 57 & 22 & 12 & 98 & 28 \\
\hline Above SSLC & 69 & 65 & 29 & 43 & 159 & 88 & 257 & 72 \\
\hline \multicolumn{9}{|c|}{ Occupation } \\
\hline Unemployed & 76 & 71.7 & 60 & 88.2 & 124 & 68.5 & 260 & 77.3 \\
\hline Employed & 30 & 28.3 & 8 & 11.8 & 57 & 31.5 & 95 & 22.7 \\
\hline \multicolumn{9}{|c|}{ Socioeconomic Status (SES) } \\
\hline Low SES & 85 & 80.2 & 54 & 79.4 & 120 & 66.3 & 259 & 72.9 \\
\hline Middle \& Upper SES & 21 & 19.8 & 14 & 20.6 & 61 & 33.7 & 96 & 27.1 \\
\hline
\end{tabular}

Of the 355 participants, $89 \%(n=314)$ were either primigravida (49\%) or second gravida (39.5\%). For 48.5\% (n=172) of them, this was their first pregnancy. Forty four percent of pregnant women were in their second trimester of pregnancy (Table 2). 


\begin{tabular}{|c|c|c|c|c|c|c|c|c|}
\hline \multirow{2}{*}{$\frac{\text { Study Variables }}{\text { Gravida }}$} & \multicolumn{2}{|c|}{ Thiruvananthapuram $(n=106)$} & \multicolumn{2}{|c|}{ Kollam (n=68) } & \multicolumn{2}{|c|}{ Ernakulam $(n=181)$} & \multicolumn{2}{|c|}{ Total $(n=355)$} \\
\hline & Number & $\%$ & Number & $\%$ & Number & $\%$ & Number & $\%$ \\
\hline One & 53 & 50.0 & 35 & 51.5 & 86 & 47.5 & 174 & 49.0 \\
\hline Two & 41 & 38.7 & 27 & 39.7 & 72 & 39.8 & 140 & 39.5 \\
\hline Three and above & 12 & 11.3 & 6 & 8.8 & 23 & 12.7 & 41 & 11.5 \\
\hline \multicolumn{9}{|c|}{ Parity } \\
\hline Zero & 54 & 50.9 & 35 & 51.5 & 83 & 45.8 & 172 & 48.5 \\
\hline One & 47 & 44.4 & 28 & 41.1 & 83 & 45.8 & 158 & 44.5 \\
\hline Two & 5 & 4.7 & 5 & 7.4 & 15 & 8.4 & 25 & 7.0 \\
\hline \multicolumn{9}{|c|}{ Gestational Age } \\
\hline$<6$ weeks & 3 & 2.8 & 6 & 8.8 & 7 & 3.9 & 16 & 4.5 \\
\hline 7-12 weeks & 27 & 25.5 & 21 & 30.9 & 40 & 22.1 & 88 & 24.8 \\
\hline 13-28 weeks & 37 & 34.9 & 35 & 51.5 & 84 & 46.4 & 156 & 44.0 \\
\hline 29-37 weeks & 39 & 36.8 & 6 & 8.8 & 50 & 27.6 & 95 & 26.7 \\
\hline
\end{tabular}

H1N1 infection rate was high among pregnant ladies compared to general population as revealed by CDC studies done during the initial phase of the outbreak. ${ }^{12}$ Present study showed that $98.3 \%(\mathrm{n}=349)$ of pregnant women seroconverted (table-3) and only 6 participants remained seronegative to pandemic H1N1 influenza indicating that almost all of the population were infected during the outbreak of H1N1 pandemic influenza in Kerala.

History regarding exposure to influenza like illness (ILI) during current pregnancy and exposure to H1N1 during pandemic period was collected during the study. $15.2 \%$ of the participants were exposed to ILI during the pandemic period.

Out of 355 pregnant ladies who participated in the study only $0.8 \%(n=5)$ had history of contact with confirmed pandemic H1N1 influenza and 1.9\% $(n=7)$ of them already received vaccination against Pandemic influenza.

\begin{tabular}{|c|c|c|c|c|}
\hline $\begin{array}{c}\text { ELISA } \\
\text { Result }\end{array}$ & $\begin{array}{c}\text { Thiruvana- } \\
\text { nthapuram }\end{array}$ & Kollam & Ernakulam & Total \\
\hline ELISA Positive & 106 & 62 & 181 & 349 \\
\hline ELISA Negative & 0 & 6 & 0 & 6 \\
\hline Seroprevalence & $100 \%$ & $91 \%$ & $100 \%$ & $98.3 \%$ \\
\hline \multicolumn{7}{|c|}{ Total } & $\mathbf{1 0 6}$ & $\mathbf{6 8}$ & $\mathbf{1 8 1}$ & $\mathbf{3 5 5}$ \\
\hline \multicolumn{7}{|c|}{ Table 3. Seroconversion Status of Study Participants } \\
\hline
\end{tabular}

\section{DISCUSSION}

This study was done among pregnant ladies from three districts of Kerala and serology showed that $98 \%$ of them had antibodies against pandemic influenza. This supported by a systematic review and meta-analysis of 55 studies conducted by Luis Furuya-Kanamori et al reported that seroprevalence varied from $13-91 \% .13$

In this study, $15.7 \%$ of pregnant women had history of exposure to influenza like illness during last pregnancy, less than one percent had exposure to proven H1N1 case and 2\% received vaccination against $\mathrm{H} 1 \mathrm{~N} 1$ pandemic influenza. This indicates that most of the pregnant ladies had subclinical infection during pandemic influenza period without any clinical manifestation. Pregnant ladies represented young population generally exposed to H1N1 pandemic influenza at the time of outbreak so they might have got exposed to H1N1 at that time. These people actually represent a cross section of the general population, high seropositivity among these groups indicates that most of the population in the study area might have had clinical or subclinical infection during the outbreak season. Epidemiological studies revealed that protection against infection lasts for many years ${ }^{14}$ indicating that most of the population in the study area are immune to further outbreaks of pandemic H1N1 influenza.

\section{CONCLUSION}

Pregnant women who participated in the study were in the age group 18 to 40 years, most of participants were of 21-30 years, most of them were unemployed and belonged to low socioeconomic status, half of them were primigravida with parity zero or one. $44 \%$ of the participants were in their second trimester of pregnancy. In contrast to 10 to $20 \%$ prevalence in other studies conducted in India and other countries, ${ }^{15,16}$ very high proportion (98.6\%) of pregnant women were sero-converted during the pandemic in Kerala.

Pregnant ladies who represent young population might have got exposed to H1N1 at that time. These people actually represent a cross section of the general population, high seropositivity among these groups indicates that most of the population residing in Thiruvananthapuram, Kollam and Ernakulam districts might have had clinical or subclinical infection during the outbreak season.

\section{ACKNOWLEDGMENTS}

The authors express thanks to the Rajeev Gandhi Institute of Biotechnology, Thiruvananthapuram for doing antibody titre estimation for the study and the staff of participating institutions who facilitated data collection.

\section{REFERENCES}

[1] WHO. Pregnancy and pandemic influenza: Information for programme managers and clinicians, 2010. www.who.int/csr/resources/publications/swineflu/ h1n1.

[2] Van Kerkhove MD, Hirve S, Koukounari A, et al. Estimating age-specific cumulative incidence for the 2009 influenza pandemic: a meta-analysis of A (H1N1)pdm09 serological studies from 19 countries. Influenza and Other Respiratory Viruses 2013;7(5): 872-86.

www.who.int/influenza 2013.

[3] Peiris JSM, Tu WW, Yen HL. A novel H1N1 virus causes the first pandemic of the 21st century. Eur J Immunol 2009;39(11):2946-54.

[4] Disaster update. www.nidm.gov.in: issue no 2471: date 30.3.2012. 
[5] Dhanya VC, Sara PJ, Sanjai D, et al. Demographic and clinical characteristics of pandemic influenza A (H1N1) 2009 Outbreak in Kerala, Southern India. British Microbiology Research Journal 2014;4(10):1142-53.

[6] Bazzo P, Djokanovic N, Koren G. H1N1 influenza in pregnancy: risks, vaccines and antivirals. Journal of Obstetrics and Gynaecology Canada. 2009;31(12):1172-5.

[7] Singhal S, Sarda N, Arora R, et al. Clinical profile \& outcome of H1N1 infected pregnant women in a tertiary care teaching hospital of Northern India. Indian J Med Res 2014;139(3):454-8.

[8] Jacob JK, Jacob SK, Samuel S, et al. Incidence and outcome of H1N1 cases in a tertiary care setting in South India. A retrospective observational study. International Journal of Scientific Study 2016;4(7):3943.

[9] WHO- H1N1 in post-pandemic period: DirectorGeneral's opening statement at virtual press conference, 10 August 2010.

[10] Luo L, Nishi K, Macleod E, et al. Expression of recombinant HA1 protein for specific detection of influenza A/H1N1/2009 antibodies in human serum. Microbiology and immunology 2013;57(1):77-81.
[11] Vijaya K, Ravikiran E. Kuppuswamy's Socio-economic status scale-updating income ranges for the year 2013. National Journal of Research in Community Medicine 2013;2(2):79-148.

[12] Jamieson DJ, Honein MA, Rasmussen SA, et al. H1N1 2009 influenza virus infection during pregnancy in the USA. Lancet 2009;374(9688):451-8.

[13] Furuya-Kanamori L, Cox M, Milinovich GJ, et al. Heterogeneous and dynamic prevalence of asymptomatic influenza virus infections. Emerging Infectious Disease 2016;22(6):1052-6.

[14] Mukherjee A, Roy T, Agrawal AS, et al. Prevalence and epidemiology of pandemic H1N1 strains in hospitals of Eastern India. Journal of Public Health and Epidemiology 2010;2(7):171-4.

[15] Reed C, Katz JM, Hancock K, et al. Prevalence of seropositivity to pandemic influenza A/H1N1virus in the United states following the 2009 pandemic. PLoS One 2012;7(10):e48187. www.plosone.org

[16] Mahmud SM, Becker M, Keynan Y, et al. Estimated cumulative incidence of pandemic (H1N1) influenza among pregnant women during the first wave of the 2009 pandemic. Canadian Medical Association Journal 2010;182(4):1522-4. 